\title{
Pharmacological and partial biochemical characterization of Bmaj-9 isolated from Bothrops marajoensis snake venom
}

Galbiatti C (1), Rocha T (2), Randazzo-Moura P (1), Ponce-Soto LA (3), Marangoni S (3), Cruz-Höfling MA (2), Rodrigues-Simioni L (1)

(1) Department of Pharmacology, Faculty of Medical Sciences, State University of Campinas (UNICAMP), Campinas, São Paulo State, Brazil; (2) Department of Histology and Embryology, Institute of Biology, State University of Campinas (UNICAMP), Campinas, São Paulo State, Brazil; (3) Department of Biochemistry, Institute of Biology, State University of Campinas (UNICAMP), Campinas, São Paulo State, Brazil.

Abstract: Bmaj-9, a basic PLA 2 (13679.33 Da), was isolated from Bothrops marajoensis snake venom through only one chromatographic step in reversed phase HPLC on $\mu$-Bondapak C-18 column. The amino acid

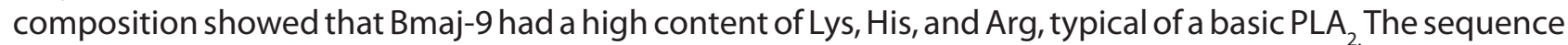
of Bmaj-9 contains 124 amino acid residues with a $p$ l value of 8.55, such as DLWQWGQMIL KETGKLPFSY YTAYGCYCGW GGRGGKPKAD TDRCCFVHDC, revealing a high homology with Asp49 PLA from other snake venoms. It also exhibited a pronounced phospholipase $A_{2}$ activity when compared with crude venom. In chick biventer cervicis preparations, the time for $50 \%$ and $100 \%$ neuromuscular paralysis was respectively (in minutes): $110 \pm 10(1 \mu \mathrm{g} / \mathrm{mL}) ; 40 \pm 6$ and $90 \pm 2(5 \mu \mathrm{g} / \mathrm{mL}) ; 30 \pm 3$ and $70 \pm 5(10 \mu \mathrm{g} / \mathrm{mL}) ; 42 \pm 1$ and 60 $\pm 2(20 \mu \mathrm{g} / \mathrm{mL})$, with no effect on the contractures elicited by either exogenous ACh $(110 \mu \mathrm{M})$ or $\mathrm{KCl}(20$ $\mathrm{mM})$. Bmaj-9 $(10 \mu \mathrm{g} / \mathrm{mL})$ neither interfered with the muscular response to direct electrical stimulation in curarized preparations nor significantly altered the release of CK at $0,15,30$ and 60 minutes incubations ( $27.4 \pm 5,74.2 \pm 8,161.0 \pm 21$ and $353.0 \pm 47$, respectively). The histological analysis showed that, even causing blockade at the maximum dosage $(5 \mu \mathrm{g} / \mathrm{mL})$, the toxin does not induce significant morphological alterations such as necrosis or infiltration of inflammatory cells. These results identified Bmaj-9 as a new member of the basic Asp49 PLA family able to interact with the motor nerve terminal membrane, thereby inducing a presynaptic neuromuscular blockade.

Key words: Bothrops marajoensis, snake venom, Asp49 PLA, neuromuscular blockade.

\section{INTRODUCTION}

The epidemiology of snakebites in Brazil has shown that the genus Bothrops accounts for the majority of accidents (1). The high incidence of snakebites has been attributed to the great number of species (over 37), their wide geographic distribution and aggressiveness, as well as a highly efficient venomous apparatus. Studies dealing with the characterization of the biochemical composition and pharmacological actions of Bothrops venoms are important from the medical point of view and as a way to understand the physiopathology of envenomations.
Undoubtedly, the study of venoms and toxins has been greatly facilitated by the development of high performance liquid chromatography (HPLC), automated Edman microsequencing, mass spectrometry and other high-end techniques (2).Phospholipase $A_{2}\left(P_{2}\right)$ is one of the most extensively studied family of snake venom proteins (3). They mostly exist as monomers. However, several of them interact with other $\mathrm{PLA}_{2}$ (or PLA_-like molecules) or with other proteins to form complexes either through covalent or noncovalent interactions. Functionally, these PLA 2 complexes exhibit presynaptic neurotoxicity being responsible for the major activity of 
bothropic venoms, assembling references on the action and molecular structure of such toxins among the most cited in the scientific literature on animal toxinology in recent years $(4,5)$.

Combined with the accompanying variety of biophysical properties, the complexity of this venom makes the search and characterization of individual venom components a daunting challenge.

In vitro studies have shown that some Bothrops venoms and their major toxins are typically myotoxic in rodents; however, neurotoxic effects have been also revealed in mouse and chick. The neurotoxicity was observed by the blockade of neuromuscular transmission, either presynaptically, in a dose range similar to that of elapid venoms, or postsynaptically (6-14).

Both the myotoxic and neurotoxic effects of Bothrops venoms have been associated with their high PLA 2 content. Secreted PLA $\mathrm{PL}_{2}\left(\mathrm{PLA}_{2}, \mathrm{EC}\right.$ 3.1.1.4) can be small basic $\mathrm{Ca}^{2+}$-dependent proteins (14 to $18 \mathrm{kDa}$ ) usually containing 5 to 8 disulfide bonds and possessing a His/Asp pair required for catalysis (2). In addition to their possible role in prey digestion, snake venom $\mathrm{PLA}_{2} \mathrm{~s}$ exhibit a wide spectrum of pharmacological effects by interfering with normal physiological processes. $\mathrm{PLA}_{2}$ effects include neurotoxic, myotoxic, anticoagulant and antiplatelet activities.

Bothrops marajoensis, an endemic snake from Marajó Island and Amazon River delta, Brazil, has been scarcely studied regarding the effects of its crude venom or its PLA 2 pharmacological action on neuromuscular junctions (15-17). The aim of this study is to analyze the Bmaj-9 action on the neuromuscular junction and its pharmacological and biochemical aspects.

\section{MATERIAL AND METHODS}

\section{Venom and Reagents \\ Bothrops marajoensis snake venom was donated (lyophilized) from Batatais Serpentarium, Batatais, state of São Paulo, Brazil. All chemicals and reagents used in this research were of analytical or sequencing grade.}

\section{Animals}

Male Hy-Line W36 chicks (4-8 days old) were obtained from the Globo Aves Agrovicola Ltd. (Brazil). The animals were kept at room temperature $\left(25 \pm 3^{\circ} \mathrm{C}\right)$ in a 12-hour light/dark cycle, with free access to food and water. All experiments were approved by the Institutional Committee for Ethics in Animal Use (CEUA/IB/ Unicamp, protocol number 1027-1) and were in accordance with the guidelines of the Brazilian Society of Laboratory Animal Science (SBCAL/ COBEA).

\section{Isolation and Purification by Reversed Phase HPLC (RP-HPLC)}

Ten milligrams of the whole venom of $B$. marajoensis were dissolved in $250 \mu \mathrm{L}$ of $0.1 \%$ $(\mathrm{v} / \mathrm{v})$ trifluoroacetic acid (TFA, solvent A) and the resulting solution was clarified by centrifugation prior to loading the supernatant onto a $\mu$-Bondapak C-18 column $(0.78 \mathrm{~cm} \times 30$ $\mathrm{cm}$; Waters 991-PDA system, USA). Proteins were eluted using a linear gradient $(0-100 \% \mathrm{v} / \mathrm{v})$ of acetonitrile in $0.1 \%(\mathrm{v} / \mathrm{v})$ TFA (solvent B), at a flow rate of $1 \mathrm{~mL} /$ minute. The elution profile was monitored at $280 \mathrm{~nm}$ and fractions were manually collected, lyophilized and stored at $-20^{\circ} \mathrm{C}$. The purified protein was referred to as Bmaj-9.

\section{SDS-PAGE}

The fractions obtained by RP-HPLC were individually submitted to tricine SDS-PAGE in a discontinuous gel and buffer system to estimate the molecular mass of the Bmaj-9 PLA 2 (18). The samples were boiled for ten minutes in a sample buffer containing $2.5 \%(\mathrm{~m} / \mathrm{v})$ SDS before electrophoresis. After the run, the gels were stained with Coomassie brilliant blue G [0.2\% $(\mathrm{m} / \mathrm{v})]$ in methanol-acetic acid-water $(4: 1: 6, \mathrm{v} / \mathrm{v})$ and maintained in the same solution without dye. The molecular mass markers used were (in $\mathrm{kDa})$ : phosphorylase $\mathrm{B}(94 \mathrm{kDa})$, albumin $(67$ $\mathrm{kDa})$, ovalbumin $(43 \mathrm{kDa})$, carbonic anhydrase $(30 \mathrm{kDa})$, soybean trypsin inhibitor $(20 \mathrm{kDa})$ and lysozyme (14 kDa) (Bio Agency, UK). For protein determination, the micro-biuret method by Itzhaki and Gill (19) was employed.

\section{MALDI-TOF Mass Spectrometric Analysis}

The molecular mass of the Bmaj-9 fraction was determined by a Voyager-DE PRO MALDI-TOF mass spectrometer (Applied Biosystems, USA). Thus, $1 \mu \mathrm{L}$ of Bmaj-9 in 0.1\% TFA was mixed with $2 \mu \mathrm{L}$ of matrix sinapinic acid (3.5-dimethoxy4-hydroxycinnamic acid) prepared using 30\% acetonitrile and $0.1 \%$ TFA. The equipment conditions were as follows: $25 \mathrm{kV}$ acceleration 
voltage, laser fixed in $2.890 \mu \mathrm{J} / \mathrm{com}^{2}$, delay of 300 ns and linear analysis mode (20).

\section{Amino Acid Sequence}

The amino acid sequence was conducted using a Pico-Tag amino acid analyzer (Waters Systems, USA) (21). The purified Bmaj-9 was hydrolyzed at $105^{\circ} \mathrm{C}$ for 24 hours in $6.0 \mathrm{M} \mathrm{HCl}$ (Pierce sequencing grade) containing $1 \%$ phenol $(\mathrm{w} / \mathrm{v})$. The hydrolysates were reacted with 20 $\mu \mathrm{L}$ of derivatization solution (ethanol:triethyla mine:water;phenylisothiocyanate, 7:1:1:1, v/v) for one hour, at room temperature. PTC-amino acids were identified and quantified by HPLC, comparing their retention times and peak areas with those from a standard amino acid mixture.

\section{Phospholipase A Activity}

$\mathrm{PLA}_{2}$ activity was determined at $\mathrm{pH} 8.0$, which was adapted for 96-well plates in the present experiment (22-24). The standard assay mixture used contained $200 \mu \mathrm{L}$ of buffer $(10 \mathrm{mM}$ Tris$\mathrm{HCl}, 10 \mathrm{mM} \mathrm{CaCl}, 100 \mathrm{mM} \mathrm{NaCl}), 20 \mu \mathrm{L}$ of substrate (4-nitro-3-octanoyloxy-benzoic acid) and $20 \mu \mathrm{L}$ of water. To measure PLA 2 activity, 20 $\mu \mathrm{L}$ of Bmaj- 9 was added to the mixture to achieve a final volume of $260 \mu \mathrm{L}$. After adding Bmaj-9, the final sample was incubated at $37^{\circ} \mathrm{C}$ for 40 minutes, and the absorbance at $425 \mathrm{~nm}$ was recorded at ten-minute intervals using a SpectraMax 340 multiwell plate reader (Molecular Devices, USA). Enzyme activity, expressed as velocity of reaction (V), was calculated based on the increase in absorbance after 20 minutes. The assays were performed in triplicate.

\section{Chick Biventer Cervicis Muscle Preparation (BC)}

Male chicks ( $\mathrm{n}=6$ for each Bmaj-9 concentration) were killed with halothane, and their biventer cervicis muscles were removed and mounted under a constant tension of $1 \mathrm{~g}$ in a $5 \mathrm{~mL}$ organ-bath containing warmed $\left(37^{\circ} \mathrm{C}\right)$, aerated $\left(95 \% \mathrm{O}_{2}+5 \% \mathrm{CO}_{2}\right)$ Krebs solution [ $(\mathrm{mM}, \mathrm{pH}$ 7.5): $\mathrm{NaCl} 118.7, \mathrm{KCl} 4.7, \mathrm{CaCl}_{2} 1.8, \mathrm{KH}_{2} \mathrm{PO}_{4} 1.17$, $\mathrm{MgSO}_{4} .7 \mathrm{H}_{2} \mathrm{O} 1.17$, glucose 11.65 and $\mathrm{NaHCO}_{3}$ 25] (25). A bipolar platinum ring electrode was placed around the muscle tendon, within which runs the motor nerve trunk supplying the muscle. Field stimulation was done using a Grass S48 stimulator (Grass Instrument Co., USA) with $0.1 \mathrm{~Hz}, 0.2 \mathrm{~ms}, 4-6 \mathrm{~V}$. Muscle contractions and contractures were recorded isometrically via a force-displacement transducer (Load Cell BG 10GM, USA) coupled to a physiograph (Gould model RS 3400, USA).

The muscle responsiveness to exogenously applied acetylcholine (ACh, $110 \mu \mathrm{M}$ for $60 \mathrm{~s}$ ) and $\mathrm{KCl}(20 \mathrm{mM}$ for $180 \mathrm{~s}$ ) was recorded in the absence of field stimulation both prior to addition of toxin (Bmaj-9) and at the end of the experiment. The BC preparation was allowed stabilizing for at least 20 minutes before addition of $\mathrm{ACh}$ or $\mathrm{KCl}$. A range of Bmaj-9 concentrations $(1,5,10$ and $20 \mu \mathrm{g} / \mathrm{mL})$ was added to the incubation bath and compared with control BC preparations incubated with Krebs solution. Experiments using $10 \mu \mathrm{g} / \mathrm{mL}$ of Bmaj-9 were done in curarized preparations (incubation with $d$-tubocurarine, $d$-Tc, $5 \mu \mathrm{g} / \mathrm{mL}$; $0.1 \mathrm{~Hz}, 2 \mathrm{~ms}, 8-20 \mathrm{~V}$ ).

\section{Creatine Kinase Activity (CK)}

Aliquots of organ bath solution $(50 \mu \mathrm{L})$ were collected at time 0 and after 15,30,60, 90 and 120 minutes of incubation of BC with toxin (10 $\mu \mathrm{g} / \mathrm{mL}, \mathrm{n}=6$ per time period). The samples were stored at $4^{\circ} \mathrm{C}$ and $\mathrm{CK}$ activity was assayed within 4 hours after the experiment, using a commercial kit (CK-NAK, Bioclin, Quibasa, Química Básica Ltd., Brazil, batch 0107). For each aliquot collected, the corresponding $50 \mu \mathrm{L}$ were replaced with fresh Krebs solution. CK activity was also assayed in control preparations without Bmaj-9. Enzyme activity was expressed in international units per liter (IU/L), with one unit of activity corresponding to phosphorylation of $1 \mu \mathrm{mol}$ of creatine $/ \mathrm{min}$ at $25^{\circ} \mathrm{C}$.

\section{Histopathological and Morphometric Analysis}

The Bmaj-9 (1 and $10 \mu \mathrm{g} / \mathrm{mL}$ ) myotoxic activity was assessed in biventer cervicis muscles, after 120 minutes of incubation, and compared with muscles incubated in Krebs solution for the same period. After, the muscles were maintained in Bouin's fixative for 24 hours, washed three times in aqueous ammonia solution, dehydrated in increasing ethanol concentrations (70\%, 90\% and $3 \times 100 \%$ ) and embedded in historesin (Leica Nublock, Germany). Sections ( $2-\mu \mathrm{m}$ thick) were obtained using a Leica RM 2035 microtome (Germany) and stained with toluidine blue for light microscopy (Olympus BX51 light microscope, Japan) analysis. Muscle images were 
captured using a digital imaging system (Image Pro Plus 6.0, Media Cybernetics Inc., USA). Three non-overlapping and non-adjacent sections were taken from each muscle. The percentage of Bmaj-9 damaged muscle fibers was assessed by multiplying the number of injured fibers (vacuolated, swollen, and heavily stained fibers) by 100 and dividing it by the total number of fibers present in the whole sectional muscle area. The results were compared with Krebs control ( $\mathrm{n}$ $=5$ per treatment). Normal fibers were considered those with both polygonal profile and myofibers evenly distributed inside the fascicle.

\section{Statistical Analysis}

All data were reported as mean ( \pm S.E.M.) of the number of animals used in each experiment. Statistical comparison of data used repeated measures ANOVA followed by the Tukey's and Kruskal-Wallis post-hoc tests. Dunn's multiple test was also performed, and all experimental groups were compared with control group, and $\mathrm{p}$ $<0.05$ indicated statistical significance.

\section{RESULTS}

\section{Biochemical Characterization of BMAJ-9}

The elution profile of $B$. marajoensis crude venom, after purification in one chromatographic step, displayed 18 peaks named according to their position from Bmaj-1 to Bmaj-18 (Figure 1). Peak 9, Bmaj-9, resulted in one small peak with a retention time of 36 minutes, eluting at $55 \%$ of solvent B. SDS-PAGE gel displayed one major protein band, indicating that Bmaj-9 fraction was obtained with high homogeneity. The Bmaj9 molecular mass, $\sim 14 \mathrm{kDa}$ (Figure 1), was confirmed by MALDI-TOF mass spectrometry (13.67933 Da) (Figure 2). Bmaj-9 PLA 2 enzymatic activity was detectable in 4-nitro-3-octanoyloxybenzoic acid substrate, being $7.9 \pm 0.5 \mathrm{nmol} /$ $\mathrm{min} / \mathrm{mg}$ compared with $2.3 \pm 1.1 \mathrm{nmol} / \mathrm{min} / \mathrm{mg}$ for $B$. marajoensis crude venom, which indicated a high catalytic activity (Figure 3). Amino acid composition determined by HPLC was: Asp/8, Glu/9, Ser/6, Gly/13, His/2, Arg/11, Thr/8, Ala/7, Pro/6, Tyr/9, Val/3, Met/1, Cys/14, Ile/5, Leu/6, Phe/ 6 and Lys/10. The higher content of Lys, Hys and Arg residues, and the positive PLA $_{2}$ activity characterized this fraction as a typical basic PLA $_{2}$ protein.

The N-terminal sequence of Bmaj9 was DLWQWGQMIL KETGKLPFSY

\section{YTAYGCYCGW}

GGRGGKPKAD

TDRCCFVHDC... An alignment of this sequence with homologous snake venom $\mathrm{PLA}_{2}$

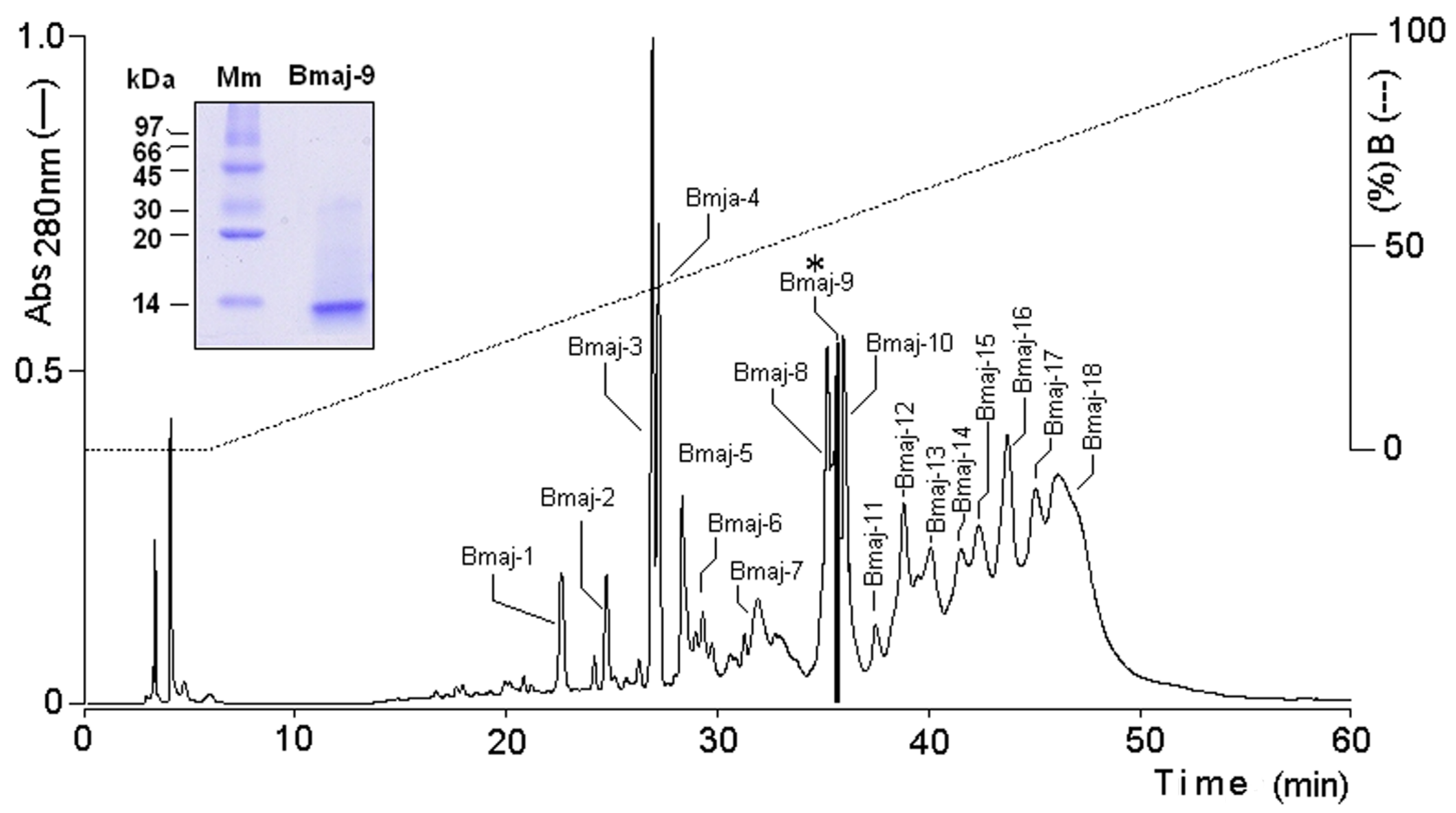

Figure 1. RP-HPLC chromatography of B. marajoensis crude venom. The elution profile ( $280 \mathrm{~nm}, 55 \%$ solvent $B$; retention time of 36 minutes) displays Bmaj-9 $\left(^{*}\right)$ as the main fraction obtained. Insert: electrophoretic profile in SDS-PAGE $(12.5 \% \mathrm{gel})$. 


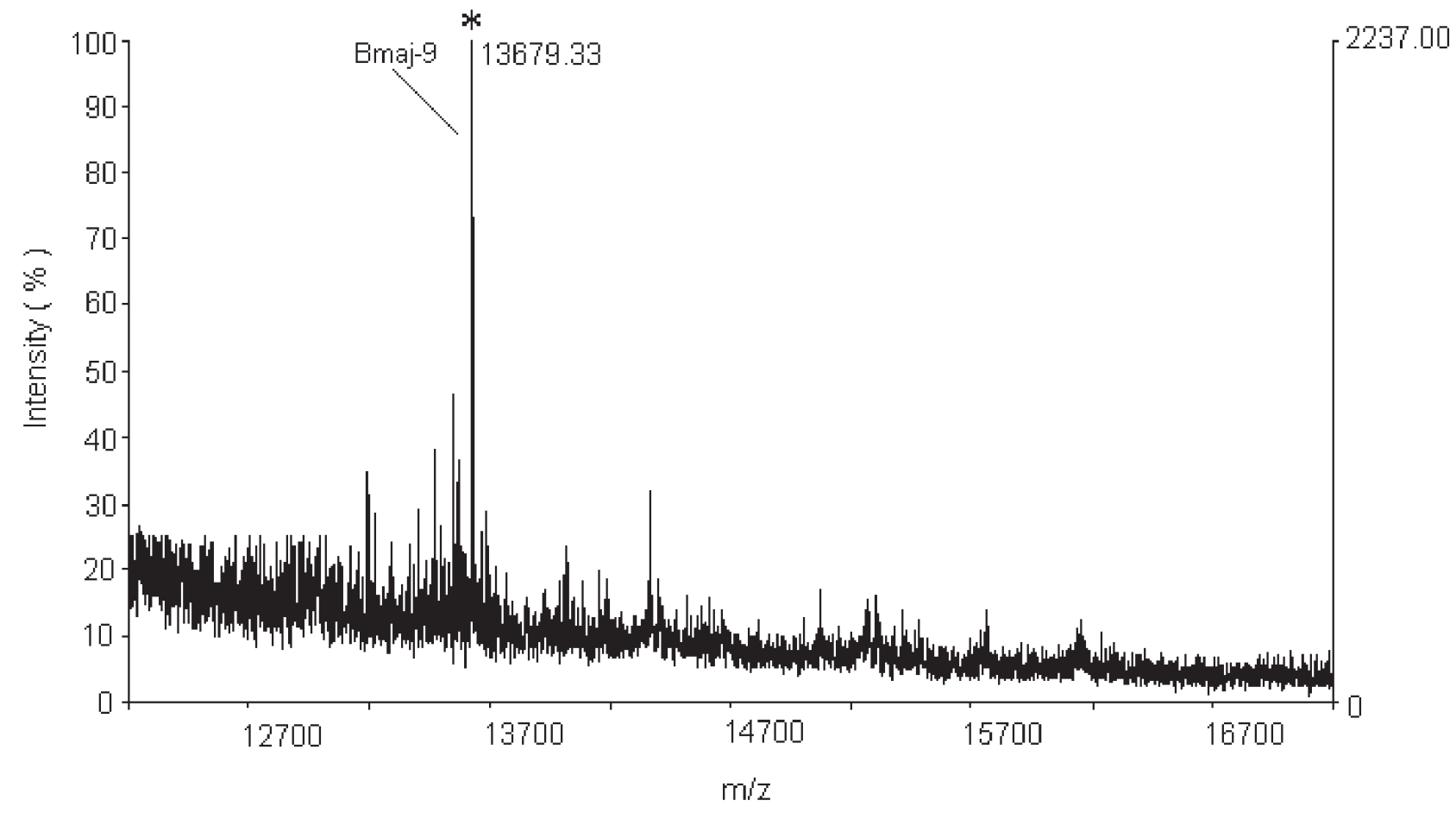

Figure 2. Bmaj-9 mass (13679.33 Da) determined by MALDI-TOF mass spectrometry.

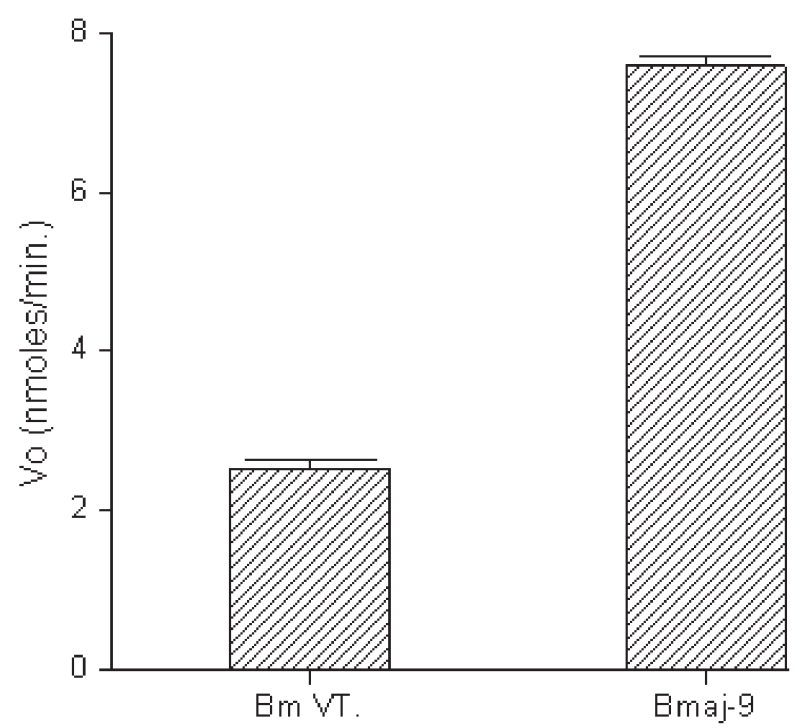

Figure 3. The graphic represents Bmaj-9 PLA enzymatic activity in comparison to $B$. marajoensis crude venom, indicating a high catalytic activity of the toxin. from Bothrops venom is shown in Figure 4. This result revealed that Bmaj-9 is an Asp49 (D49).

Considering that this protein is an important molecule that acts by blocking the neuromuscular junction presynaptically, the partial sequence of PLA from Bothrops marajoensis snake venom in this study was submitted to Universal Protein Resource (UniProt - http://www.uniprot.org). The code is B3A0N3 and its similarities with the homologous snake venom PLA, shown in Figure 4 are: $92 \%$ to PLA $_{2}$ BmjeTX-II, $88 \%$ to PLA $_{2}$ BmjeTX-I, 86\% to PLA 2 6-2, 78\% to PLA $26-1$ and PLA 2 BmjeTX-I.

\section{Twitch Tension Recording of BC}

Bmaj-9 $(1,5,10$ and $20 \mu \mathrm{g} / \mathrm{mL})$ induced an irreversible neuromuscular blockade in $\mathrm{BC}$ preparation, which was time/concentrationdependent even after several washes (Figure 5 - A). According to toxin concentration, the

10 20 30

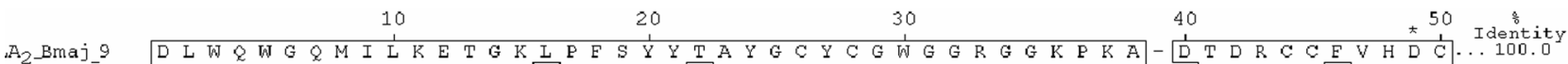
$\mathrm{A}_{2}$ BmjeTX II D L W Q

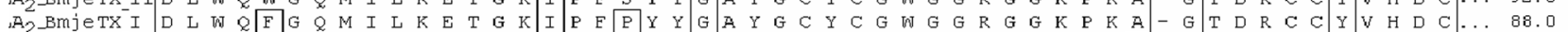

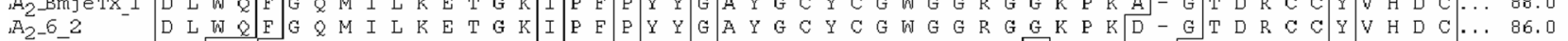

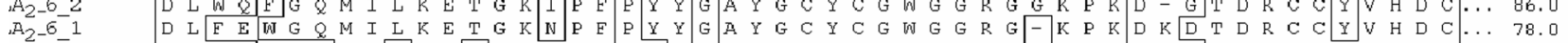

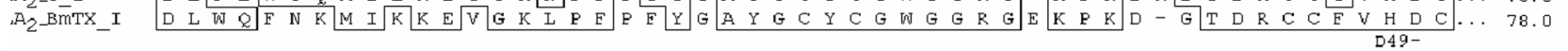

Figure 4. N-terminal amino acid sequence of Bmaj-9 compared with other Asp49 PLA . BmjeTX-I and -II from B. marajoensis venom, 6-1 and 6-2 toxins from B. jararacussu venom and BmTX-I from B. moojeni venom. 


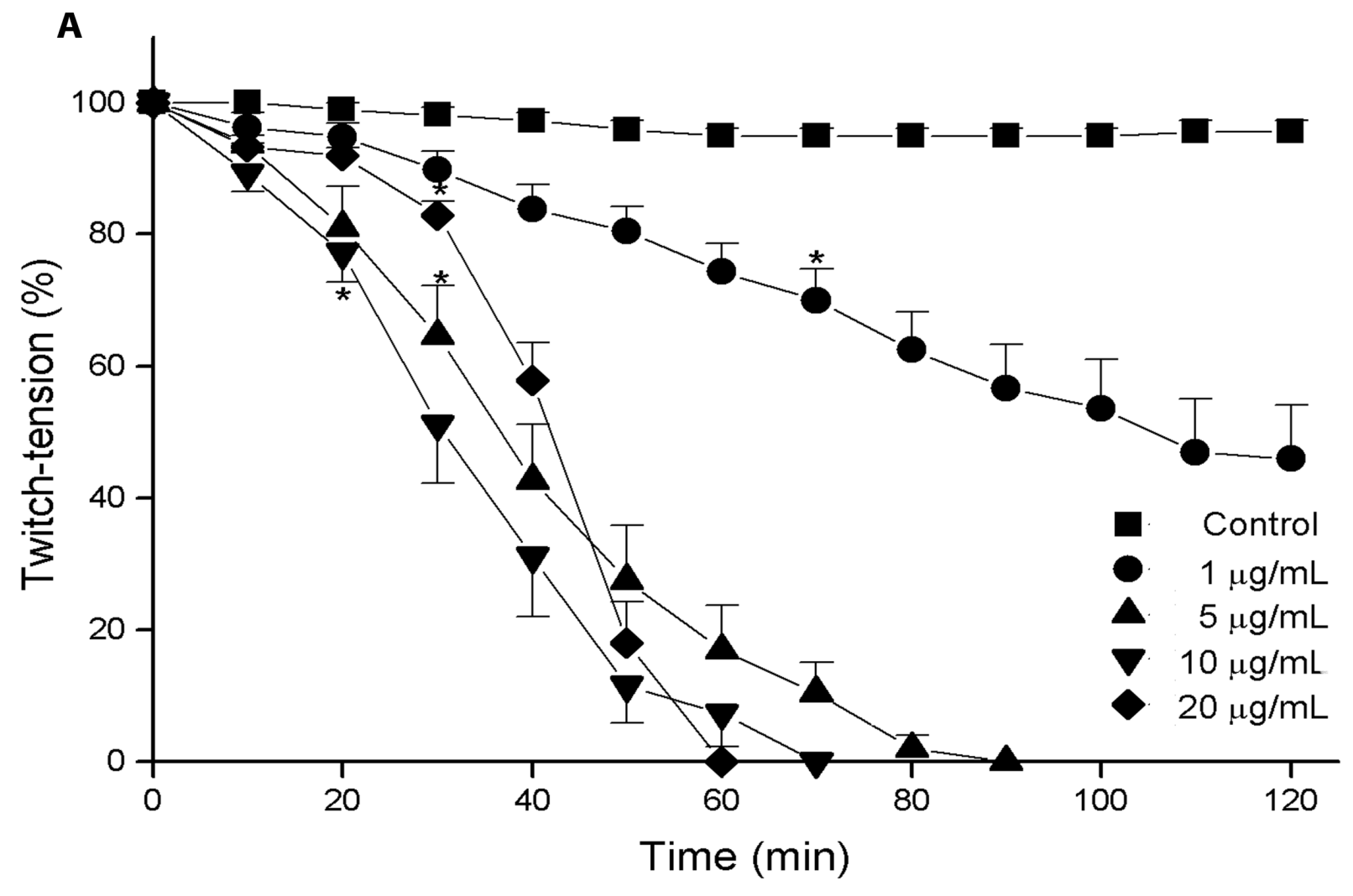

B
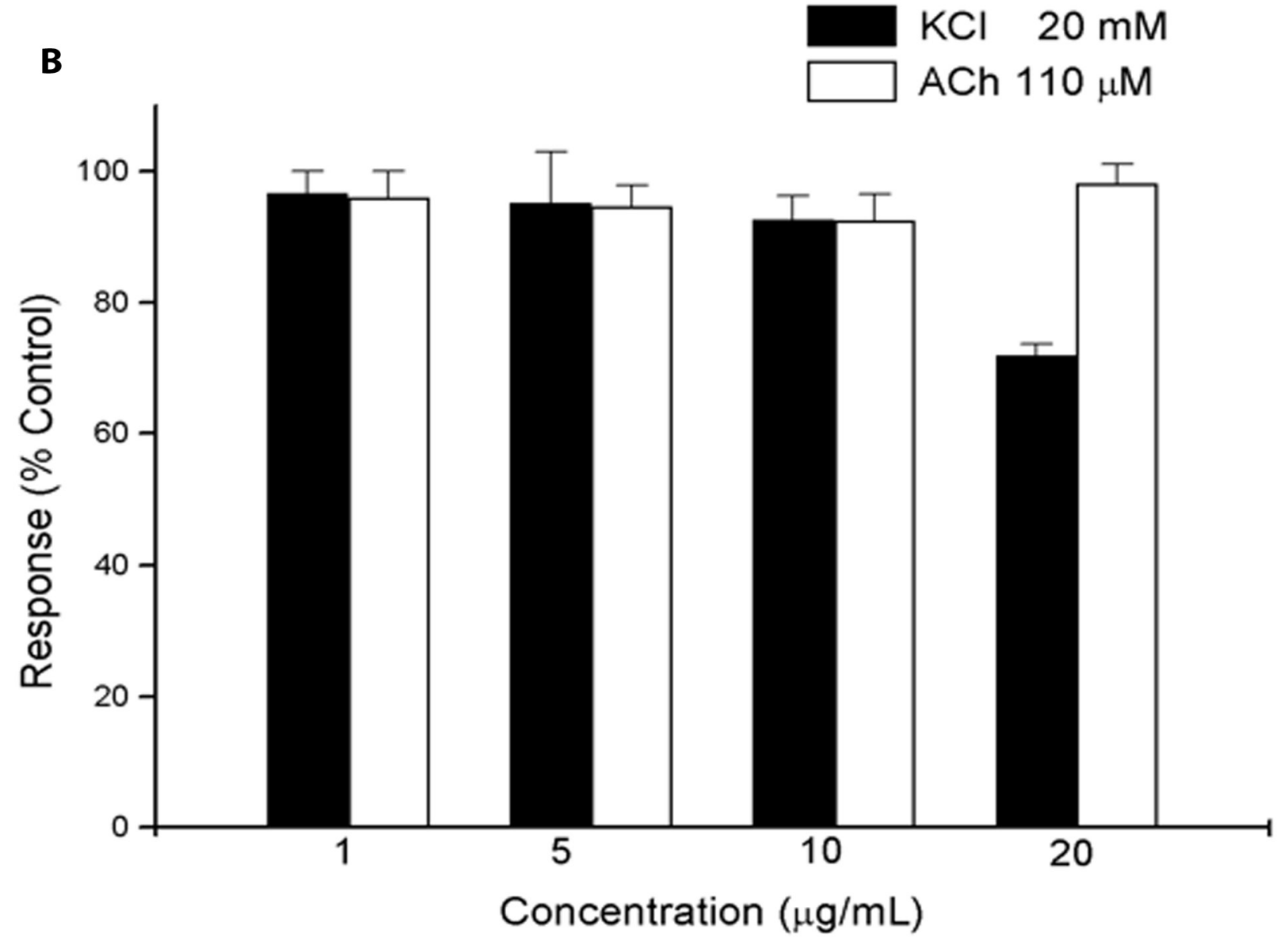

Figure 5. (A) Neuromuscular blockade induced by crescent concentrations $(1,5,10$ and $20 \mu \mathrm{g} / \mathrm{mL})$ of Bmaj9 in BC preparation. Note the irreversible twitch-tension neuromuscular blockade for 5,10 and $20 \mu \mathrm{g} / \mathrm{mL}$ concentrations. (B) The graphic represents the effect on contractures to exogenous acetylcholine (ACh) and potassium $(\mathrm{KCl})$. Each point is the mean \pm S.E.M. $\left({ }^{*} \mathrm{p}<0.05\right)$. 

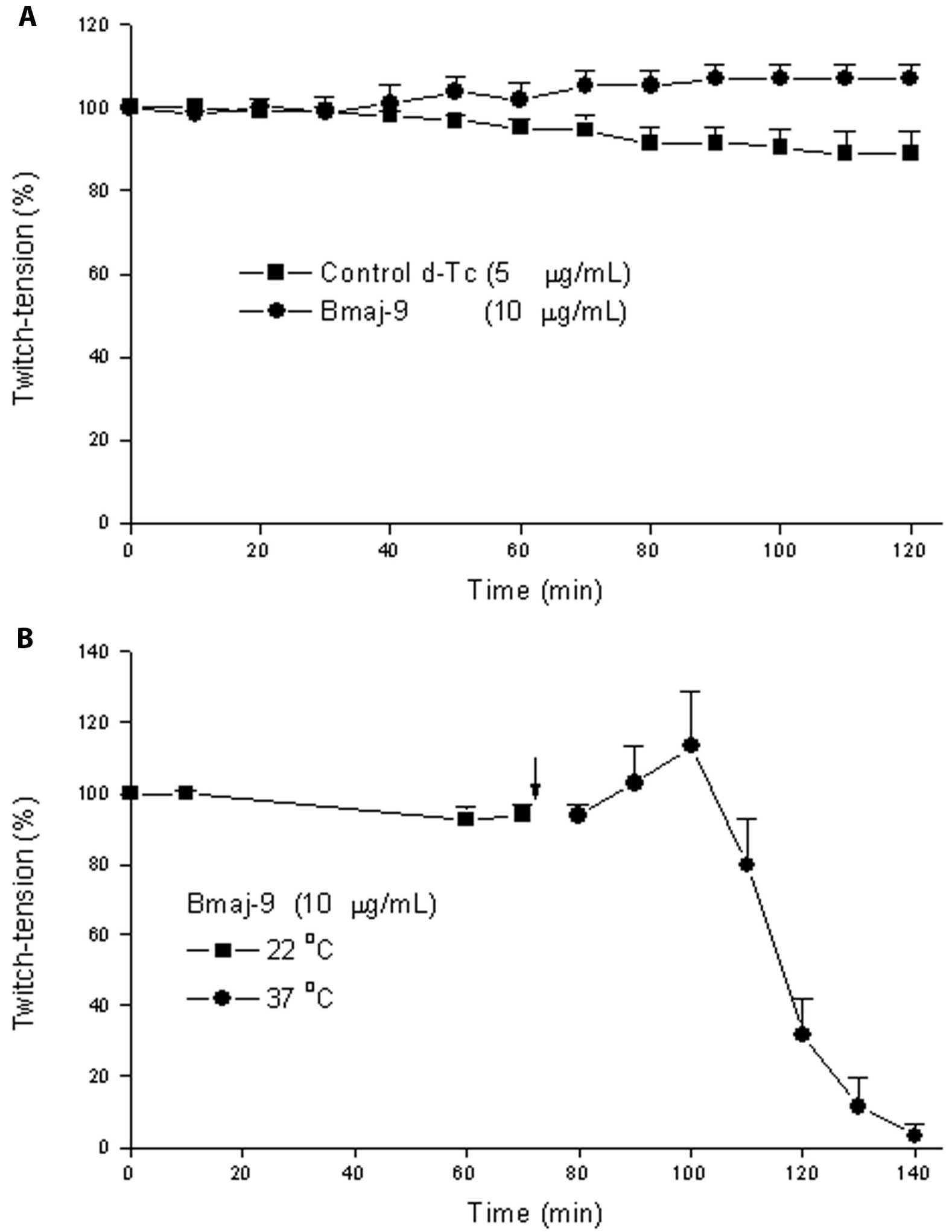

Figure 6. (A) Effect of Bmaj-9 $(10 \mu \mathrm{g} / \mathrm{mL})$ on curarized preparations. Note the absence of effect in the muscular response to direct electrical stimulation. (B) The characteristic neuromuscular blockade was not observed when the preparations were incubated with Bmaj-9 $(10 \mu \mathrm{g} / \mathrm{mL})$ at low temperature $\left(22^{\circ} \mathrm{C}\right)$. 

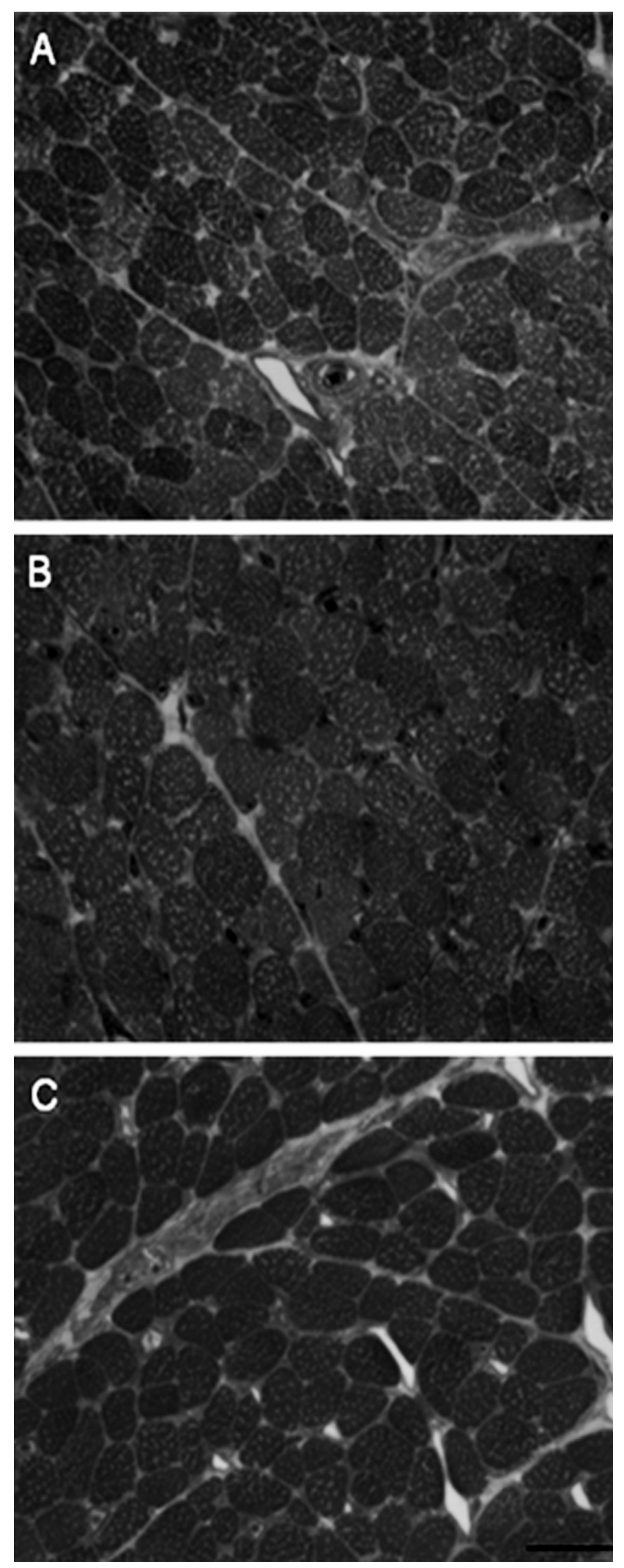

Figure 7. Morphological aspects of $B C$ muscle after 120 minutes of incubation: (A) Krebs control, (B) 1 $\mu \mathrm{g} / \mathrm{mL}$ and (C) $10 \mu \mathrm{g} / \mathrm{mL}$ Bmaj-9. Note the preserved polygonal cross-sectional profile of muscle fibers in all treatments. No damage was detected in muscle fibers. $\operatorname{Bar}=50 \mu \mathrm{m}$. time to achieve $50 \%$ neuromuscular paralysis after indirect electrical stimulation was: $110 \pm 10$ minutes $(1 \mu \mathrm{g} / \mathrm{mL}), 40 \pm 6$ minutes $(5 \mu \mathrm{g} / \mathrm{mL}), 30$ \pm 3 minutes $(10 \mu \mathrm{g} / \mathrm{mL})$ and $42 \pm 1$ minutes $(20$ $\mu \mathrm{g} / \mathrm{mL}$ ), whereas the time to reach $100 \%$ blockade was $90 \pm 2$ minutes $(5 \mu \mathrm{g} / \mathrm{mL}), 70 \pm 5$ minutes $(10$ $\mu \mathrm{g} / \mathrm{mL})$ and $60 \pm 2$ minutes $(20 \mu \mathrm{g} / \mathrm{mL})(\mathrm{n}=5$ per dose), all of them significantly different from control $(\mathrm{p}<0.05)$.

Note that Bmaj-9 concentrations ranging from 5 to $20 \mu \mathrm{g} / \mathrm{mL}$ exhibited similar blocking potency, indicating that, at the present experimental condition, $5 \mu \mathrm{g} / \mathrm{mL}$ represents the minimal dose to cause total twitch tension paralysis (Figure 5 A). The contractures induced by exogenous ACh $(110 \mu \mathrm{M})$ or $\mathrm{KCl}(20 \mathrm{mM})$ remained unchanged regardless the toxin concentration assayed (Figure 5 - B).

Conversely, in curarized preparations directly stimulated, Bmaj-9 PLA did not affect the muscular contractile response (Figure $6-\mathrm{A}$ ). In addition, at a lower temperature $\left(22^{\circ} \mathrm{C}\right)$, the toxin $(10 \mu \mathrm{g} / \mathrm{mL})$ did not induce the characteristic neuromuscular blockade seen at $37^{\circ} \mathrm{C}$ with the same concentration and time interval (Figure $6-\mathrm{B}$ ).

\section{CK Activity}

Incubation with Bmaj-9 $(10 \mu \mathrm{g} / \mathrm{mL})$ at 0,15 , 30 and 60 minutes did not significantly alter the release of $\mathrm{CK}$ in $\mathrm{BC}(27.4 \pm 5,74.2 \pm 8,161.0$ \pm 21 and $353.0 \pm 47)$ when compared with the corresponding controls $(37.7 \pm 12,111.5 \pm 26$, $142.1 \pm 23$ and $248.2 \pm 50$ ). However, at 90 and 120 minutes of toxin exposure there was a mild but significant increase of CK activity compared with control (494.7 \pm 50 and $812.6 \pm 95$ versus $331.0 \pm 44$ and $414.6 \pm 67$, respectively $\mathrm{p}<0.05)$.

\section{Histological Analysis}

The calculation of damages caused by different Bmaj- 9 concentrations $(1,10,20$ and $40 \mu \mathrm{g} / \mathrm{mL}$, $\mathrm{n}=5$ ) of BC muscle after 120 minutes of indirect electrical stimulation showed the following negligible percentages of damaged fibers: 0.11 $\pm 0.1,0.70 \pm 0.6,0.01 \pm 0.01$ and $3.56 \pm 1.4 \%$ (data not shown), which did not differ from the Krebs solution $(0.90 \pm 0.41)$. Figure 7 shows that the muscle fiber morphology practically did not differ in the biventer cervicis muscle incubated with Krebs solution (Figure $7-A$ ) or with 1 and $10 \mu \mathrm{g} / \mathrm{mL}$ of Bmaj-9 (Figures $7-\mathrm{B}$ and $\mathrm{C}$, respectively). 


\section{DISCUSSION}

Snake venom $\mathrm{PLA}_{2}$ enzymes typically exist in venoms as monomers and sometimes as complexes formed between PLA 2 enzymes, as well as with other proteins, by covalent or noncovalent interactions. Snake venoms often contain many isoforms or isoenzymes, and therefore care must be taken during purification to separate them, as isoforms or isoenzymes may induce different pharmacological effects through their interaction with protein receptors/acceptors. This specific interaction with their target protein is mediated through specific pharmacological sites on the molecular surface. Upon binding to their target protein, they induce their effects, which may be dependent or independent of enzymatic activity (26).

One chromatographic step identified a new basic toxin, coined as Bmaj-9, which was shown to be similar to other snake venom $\operatorname{PLA}_{2} s(20,27$ 28). Bmaj-9 amino acid composition showed a high content of basic and hydrophobic residues, with 14 half-Cys. The N-terminal amino acid sequence revealed a high level of homology among Bmaj-9 from B. marajoensis venom and other toxins from the same venom species, such as D49 PLA 2 s, BmjeTX-I and BmjeTX-II isoforms, 6-1 and 6-2 toxins from B. jararacussu venom and BmTX-I from B. moojeni venom (20, 27-28). Studies on sequence homology of Bmaj-9 showed an extremely conserved position in $\mathrm{PLA}_{2}$ amino acids. At positions 1 and 2, amino acid sequence SL are prevalent; at position 4, amino acid Q; at positions 7-10, amino acids KMIL; at positions 12 and 13, amino acids ET; at position 21, amino acid Y; at positions $25-26$ and Y28, G30, G32, D49, H48 and Y52 are directly or indirectly linked in the catalysis of Bmaj-9. In Asp49 PLA $_{2}$ s there are many conserved residues that have important functions in the expression of the PLA 2 activity (29).

Bmaj-9 reveals a high sequential homology in the $\mathrm{N}$-terminal region with $\mathrm{PLA}_{2}$ from snake venoms displayed at positions $2(\mathrm{~L}), 4(\mathrm{Q}), 8-10$ (MIL) and 12-13 (ET), except for one substitution. Only one difference in the $\mathrm{N}$-terminal sequence of Bmaj-9 consisted of replacement $\mathrm{S} 1 \rightarrow \mathrm{D} 1, \mathrm{I} 16$ $\rightarrow \mathrm{L} 16, \mathrm{G} 22 \rightarrow \mathrm{T} 22, \mathrm{G} 40 \rightarrow \mathrm{D} 40$ and $\mathrm{Y} 46 \rightarrow \mathrm{F} 46$. The amino acid differences in the $\mathrm{N}$-terminal sequence did not decrease either the catalytic or the pharmacologic activity of Bmaj-9 PLA 2 .
Our findings showed that Bmaj-9 has potent neurotoxic activity, since concentrations as low as 1 and $5 \mu \mathrm{g} / \mathrm{mL}$ can lead to the blockade of the muscle contractile response in $\mathrm{BC}$ preparations. Bmaj-9 PLA 2 neuromuscular activity was higher than the exhibited by the whole venom. Although envenomations by Bothrops snakes produce no neurotoxic clinical signs, venoms from several species can cause neuromuscular blockade in vitro and produce signs of peripheral muscular weakness in chickens and mice (7). Other PLA isolated from other bothropic venoms have also shown neurotoxic effects $(3,17,26,27)$.

Thus, only B. jararacussu, $B$. insularis and $B$. pauloensis venoms were satisfactorily investigated regarding this activity, including the isolation of neurotoxic components, all of them with presynaptic effects, which were mainly due to $\mathrm{PLA}_{2}(6,30,31)$.

Bmaj-9 PLA from B. marajoensis venom induced an irreversible twitch-tension neuromuscular blockade at several toxin concentrations $(1,5,10$ or $20 \mu \mathrm{g} / \mathrm{mL})$ without interfering with $\mathrm{ACh}$ and $\mathrm{KCl}$ induced contractures, hence characterizing this fraction as neurotoxic. In fact, even after twitch-tension complete paralysis (after 60 minutes of incubation with $10 \mu \mathrm{g} / \mathrm{mL}$ of Bmaj-9), neither muscle damage (fiber morphology, CK activity and response to direct stimulation) nor $\mathrm{KCl}$ response remained unchanged, hence showing absence of muscular effect. The findings indicate that Bmaj- 9 could be included in the group of PLA 2 neurotoxins at least in the present experimental conditions.

The fact that the neuromuscular effect of Bmaj9 was temperature-dependent suggests a role of the enzymatic activity in its neuromuscular action. In support to this view, a high catalytic activity was found for neuwieditoxin-I and -II from B. neuwiedi pauloensis venom (as per Bmaj9, also Asp49 PLA 2 s), and whose neuromuscular blockade also depends on the temperature (6).

All together, these results identify Bmaj-9, isolated from $B$. marajoensis venom, as a new member of the Asp49 PLA family, which acts by blocking the neuromuscular junction in presynaptic sites.

\section{ACKNOWLEDGMENTS}

The authors are grateful to Mr. Paulo A. Baldasso and Mr. Gildo B. Leite for technical assistance. This work was supported by the National Council 
for Scientific and Technological Development $(\mathrm{CNPq})$ and was part of a master's thesis developed by Charlene Galbiatti.

\section{COPYRIGHT}

(C) CEVAP 2012

\section{SUBMISSION STATUS}

Received: June 22, 2011.

Accepted: November 4, 2011.

Abstract published online: November 28, 2011. Full paper published online: February 28, 2012.

\section{CONFLICTS OF INTEREST}

The authors declare no conflicts of interest.

\section{FINANCIAL SOURCE}

The National Council for Scientific and Technological Development $(\mathrm{CNPq})$ provided the financial grants.

\section{ETHICS COMMITTEE APPROVAL}

The present study was approved by the Institutional Committee for Ethics in Animal Use (CEUA/IB/Unicamp, protocol number 1027-1). Moreover, all tests were in accordance with the guidelines of the Brazilian Society of Laboratory Animal Science (SBCAL/COBEA).

\section{CORRESPONDENCE TO}

Léa Rodrigues-Simioni, Faculdade de Ciências Médicas, Universidade Estadual de Campinas, Rua Tessália Vieira de Camargo, 126, Cidade Universitária "Zeferino Vaz", Barão Geraldo, Campinas, SP, 13083-887, Brasil. Phone: +55 193521 9533. Fax: +55 193289 2968. Email: simioni@unicamp.br.

\section{REFERENCES}

1. Bochner R, Struchiner CJ. Snake bit epidemiology in the last 100 years in Brazil: a review. Cad Saúde Pública. 2003;19(1):7-16.

2. dos Santos LD, da Silva Menegasso AR, dos Santos Pinto JR, Santos KS, Castro FM, et al. Proteomic characterization of the multiple forms of the PLAs from the venom of the social wasp Polybia paulista. Proteomics. 2011;11(8):1403-2.

3. Kini RM. Excitement ahead: structure, function and mechanism of snake venom phospholipase A2 enzymes. Toxicon. 2003;42(2):827-40.

4. Bon C. Multicomponent neurotoxic phospholipase $\mathrm{A}_{2}$. In Kini RM (editors). Phospholipase A2 enzyme: structure, function and mechanism. Chichester: Wiley; 1997. p. 269-85.
5. de Lima ME, Fontes-Dias CL, Carlini CR, Guimarães JA. Toxinology in Brazil: A big challenge for a rich biodiversity. Toxicon. 2010;56(7):1084-91.

6. Borja-Oliveira CR, Kassab BH, Soares AM, Toyama $\mathrm{MH}$, Giglio JR, Marangoni S, et al. Purification and $\mathrm{N}$-terminal sequencing of two presynaptic neurotoxic $\mathrm{PLA}_{2}$, Neuwieditoxin-I and Neuwieditoxin-II, from Bothrops neuwiedi pauloensis (jararaca pintada) venom. J Venom Anim Toxins incl Trop Dis. 2007;13(1):103-21.

7. Cogo JC, Prado-Franceschi J, Cruz-Hofling MA, Corrado AP, Rodrigues-Simioni L. Effect of Bothrops insularis venom on the mouse and chick nerve-muscle preparation. Toxicon. 1993;31(10):1237-47.

8. Oshima-Franco Y, Leite GB, Belo CA, Hyslop S, Prado-Franceschi J, Cintra AC, et al. The presynaptic activity of bothropstoxin-I, a myotoxin from Bothrops jararacussu snake venom. Basic Clin Pharmacol Toxicol. 2004;95(4):175-82.

9. Rodrigues-Simioni L, Zamunér SR, Cogo JC, BorjaOliveira CR, Prado-Franceschi J, da Cruz-Höfling MA, et al. Pharmacological evidence for a presynaptic action of venoms from Bothrops insularis (jararaca ilhoa) and Bothrops neuwiedi (jararaca pintada). Toxicon. 2004;43(6):633-8.

10. de Abreu VA, Leite GB, Oliveira CB, Hyslop S, Furtado M de F, Simioni LR. Neurotoxicity of Micrurus altirostris (Uruguayan coral snake) venom and its neutralization by commercial coral snake antivenom and specific antiserum raised in rabbits. Clin Toxicol. 2008;46(6):519-27.

11. Goularte FC, Cruz-Höfling MA, Cogo JC, Gutiérrez JM, Rodrigues-Simioni L. The ability of specific antivenom and low temperature to inhibit the myotoxicity and neuromuscular block induced by Micrurus nigrocinctus venom. Toxicon. 1995;33(5):679-89.

12. Serafim FG, Reali M, Cruz-Höfling MA, Fontana MD. Action of Micrurus dumerilii carinicauda coral snake venom on the mammalian neuromuscular junction. Toxicon. 2002;40(2):167-74.

13. Randazzo-Moura P, Ponce-Soto LA, RodriguesSimioni L, Marangoni S. Structural characterization and neuromuscular activity of a new Lys49 phospholipase (A2) homologous (Bp-12) isolated from Bothrops pauloensis snake venom. Protein J. 2008;27(6):355-62.

14. Rodrigues-Simioni L, Borgese N, Ceccarelli B. The effects of Bothrops jararacussu venom and its components on frog nerve-muscle preparation. Neuroscience. 1983;10(2):475-89.

15. Campbell JA, Lamar WW. The Venomous Reptiles of the Western Hemisphere: Comstock Publishing Associates, Cornell University Press, Ithaca, New York; 2004.

16. Evangelista IL, Martins AM, Nascimento NR, Havt A, Evangelista JS, de Norões TB, et al. Renal and cardiovascular effects of Bothrops marajoensis venom and phospholipase A. Toxicon. 2010;55(6):1061-70.

17. Galbiatti C, Leite GB, Marangoni S, Ponce-Soto LA, Cavalcante WLG, Bonfim VL, et al. Neuromuscular 
activity of a phospholipase $\mathrm{A}_{2}$ from Bothrops marajoensis venom. J Venom Anim Toxins incl Trop Dis. 2007;13(1):321.

18. Schägger $\mathrm{H}$, von Jagow $\mathrm{G}$. Tricine-sodium dodecyl sulfate-polyacrylamide gel electrophoresis for the separation of proteins in the range from 1 to $100 \mathrm{kDa}$. Anal Biochem. 1987;166(2):368-79.

19. Itzhaki RF, Gill DM. A micro-biuret method for estimating proteins. Anal Biochem. 1964;9:401-10.

20. Ponce-Soto LA, Bonfim VL, Rodrigues-Simioni L, Novello JC, Marangoni S. Determination of primary structure of two isoforms 6-1 and 6-2 PLA D49 from Bothrops jararacussu snake venom and neurotoxic characterization using in vitro neuromuscular preparation. Protein J. 2006; 25(2):147-55.

21. Heinrikson RL, Meredith SC. Amino acid analysis by reverse-phase high-performance liquid chromatography: precolumn derivatization with phenylisothiocyanate. Anal Biochem. 1984;136(1):6574.

22. Cho W, Kézdy FJ. Chromogenic substrates and assay of phospholipases A. Methods Enzymol. 1991;197:7579.

23. Holzer M, Mackessy SP. An aqueous endpoint assay of snake venom phospholipase $\mathrm{A}_{2}$. Toxicon. 1996;34(10):1149-55.

24. Ponce-Soto LA, Toyama MH, Hyslop S, Novello JC, Marangoni S. Isolation and preliminary enzymatic characterization of a novel PLA from Crotalus durissus collilineatus venom. J Protein Chem. 2002;21(3):131-6.
25. Ginsborg BL. Some properties of avian skeletal muscle fibres with multiple neuromuscular junctions. J Physiol. 1960;154:581-98.

26. Doley R, Kini RM. Protein complexes in snake venom. Mol Cell Life Sci. 2010;66(17):2851-71.

27. Ponce-Soto LA, Martins-de-Souza D, Marangoni S. Neurotoxic, myotoxic and cytolytic activities of the new basic PLA ${ }_{2}$ ) isoforms BmjeTX-I and BmjeTXII isolated from the Bothrops marajoensis (Marajó Lancehead) snake venom. Protein J. 2010;29(2):10313.

28. Calgarotto AK, Damico DC, Ponce-Soto LA, Baldasso PA, Da Silva SL, Souza GH, et al. Biological and biochemical characterization of new basic phospholipase $\mathrm{A}_{2}$ BmTX-I isolated from Bothrops moojeni snake venom. Toxicon. 2008;51(8):1509-19.

29. Arni RK, Ward RJ. Phospholipase $A_{2}-A$ structural review. Toxicon. 1996; 34(8):827-41.

30. VL Bonfim, Toyama MH, Novello JC, Hyslop S, Oliveira CR, Rodrigues-Simioni L, et al. Isolation and enzymatic characterization of a basic phospholipase $\mathrm{A}_{2}$ from Bothrops jararacussu snake venom. J. Protein Chem. 2001;20(3):239-45.

31. Cogo JC, Prado-Franceschi J, Giglio JR, Corrado AP, Cruz-Höfling MA, Donato JL, et al. An unusual presynaptic action of Bothrops insularis snake venom mediated by phospholipase $\mathrm{A}_{2}$ fraction. Toxicon. 1998;36(10):1323-32. 